\title{
EROTOMANIA: OS IMPASSES DO AMOR E UMA RESPOSTA PSICÓTICA*
}

Juliana Bressanelli e Antônio M. Ribeiro Teixeira

Juliana Bressanelli

Mestre em Estudos

Psicanalíticos

pelo Programa

de Pós-graduação

em Psicologia

da Universidade

Federal de Minas

Gerais (UFMG),

psicóloga pela

Universidade

Federal do Espírito

Santo.

Antônio M. Ribeiro

Teixeira

Professor adjunto

da UFMG, doutor

em Psicanálise pela

Universidade de

Paris VIII, mestre

em Filosofia pela

UFMG, médico pela

UFMG.
RESUMO: Aborda-se o conceito de erotomania como uma resposta dada pelo sujeito psicótico para a questão que se apresenta ao ser humano, provocada pela contingência inerente ao encontro com o parceiro amoroso. Estabelece-se de que forma o amor se coloca como problema para o ser humano e trabalhamos essa perspectiva apontando para a especificidade da erotomania em sua diferenciação com a resposta oferecida pelo sujeito neurótico, o amor de transferência.

Palavras-chave: Erotomania, psicose, transferência, amor.

ABSTRACT: Erotomania: the impasses of love and a psychotic response. It consists of approaching the concept of Erotomania as a response given by the psychotic for the question that is presented to the human being, caused by the contingency inherent to the encounter with the loving partner. We establish how love sets up a problem to the human being and we work this perspective pointing out the specificity of Erotomania in its differentiation with the response given by the neurotic, which is, the loving transference. Keywords: Erotomania, psychosis, transference, love.

\footnotetext{
* Esse artigo é fruto da dissertação com o título "A erotomania como resposta psicótica aos impasses do amor" para a UFMG, de Juliana Bressanelli, orientada pelo prof. Antônio Márcio Ribeiro Teixeira, apresentada no ano de 2007.
} 
notório que a teoria psicanalítica foi capaz de situar um lugar de importância para o estudo das psicoses e assegurar um posto para suas construções subjetivas. Esta importância é dada não apenas ao reconhecimento de um espaço de dignidade para esses sujeitos, mas principalmente na consideração da relevância de seu lugar em uma transmissão. Lacan, na época da publicação de sua tese de doutorado (1932/1987), nos dá mostras de suas raízes profundamente psiquiátricas, mas sem deixar de evocar algo que não mudaria ao longo do tempo em sua prática: a importância e a atenção dispensadas à fala do paciente. Assim, foi capaz de ultrapassar um debate acomodado em uma psiquiatria biológica e medicalizante.

Que neuróticos e psicóticos têm maneiras diferentes de se situar com relação ao Outro, à linguagem, ao próprio gozo, não é novidade no que diz respeito à teoria psicanalítica. Entretanto, fica para nós a questão de como esses sujeitos, em suas diferenças, se situam frente à questão do amor.

Não raro, os psicanalistas têm que lidar com a presença do fenômeno erotomaníaco em seu trabalho com pacientes psicóticos. E da mesma forma que o analista deve manejar a transferência - que eventualmente pode apresentar tonalidades eróticas, o que configura certo embaraço clínico - a Erotomania pode oferecer um impasse difícil de contornar.

\section{CLÉRAMBAULT E A SÍNDROME EROTOMANÍACA}

Quando nos referimos à erotomania, é importante mostrar o caminho percorrido pelo conceito desde sua primeira menção. Célebre psiquiatra francês, Gaëtan Gatian de Clérambault (1872/1934) destacou-se por sua descrição pioneira da síndrome erotomaníaca, que fez de forma ampla e magistral.

Clérambault tinha o estilo pessoal de abordagem clínica investigativa que era, provavelmente, consequência de seu contexto de trabalho, num campo de observação privilegiado. Clérambault não tinha o simples intuito de buscar a causa orgânica do delírio, mas principalmente de penetrar na linguagem, na realidade simbólica do sujeito. Seu trabalho já apontava para a importância dos fenômenos de linguagem que se apresentam na psicose.

Em sua elaboração sobre a síndrome do automatismo mental, a psicose alucinatória crônica se decomporia em duas partes: um núcleo que seria o automatismo e uma superestrutura que seria o delírio. Clérambault considera a existência de um início através de fenômenos sutis, em princípio abstratos, e que depois vão se aproximando da forma verbal. São fenômenos de interferência, que perturbam o curso do pensamento, mas que não têm conteúdo num primeiro momento. É o que o autor chama de pequeno automatismo mental. À medida que a tendência à verbalização vai progredindo, o pequeno automatismo passa a apresentar fenô- 
menos ideoverbais. De maneira gradativa, o pensamento que era indiferenciado vai se tornando auditivo e verbomotor: as vozes passam a ser verbais, objetivas, individualizadas e temáticas. Às alucinações auditivas podem associar-se outros fenômenos alucinatórios, motores (sensações de movimento, fenômenos de inibição psicomotora, atos automáticos, emissões verbais involuntárias, etc.) ou sensitivos (cenestopatias, alucinações genitais). O chamado grande automatismo ou automatismo tríplice é justamente mental, motor e sensitivo. Percebemos a profunda raiz mecanicista que persiste no trabalho de Clérambault através da sua explicação dos fenômenos de automatismo mental, que teriam uma base orgânica definida, ainda que desconhecida e postulada. Apesar disso, a construção teórica operada por este autor era movimentada por uma paixão clínica incontestável. Para ele, o mecanismo da Erotomania seria fundamentalmente psicológico - ele defendia a existência de um mecanismo psicogenético das psicoses paranoicas —, ao contrário das demais psicoses, cuja estrutura calcada nos fenômenos de automatismo mental seria eminentemente orgânica.

Podemos perceber aí, então, a herança "clérambaultiana” no trabalho de Lacan. Além de certa concepção "estruturalista” da psicose, Clérambault chama a atenção para o caráter verbal do fenômeno alucinatório. Verbal, e não propriamente auditivo, o que corresponderia justo à ideia do significante e da determinação simbólica das estruturas psíquicas, marca fundamental do primeiro tempo do ensino de Lacan. Assim, nos damos conta de que a questão da incidência da linguagem sobre o psiquismo já estava presente em suas elaborações e podemos dizer, decerto, que influenciaram diretamente a concepção lacaniana da psicose. Ao mesmo tempo, é importante salientar que Clérambault se interessava pela busca da posição do doente no lugar mesmo de sua loucura, numa leitura estrutural que levava em conta a particularidade de cada caso.

Aquele que Lacan designa como seu único mestre em psiquiatria, também descrito por Bercherie (1989) como "um verdadeiro talento de observação analítica”, Clérambault destacava-se por um estilo muito próprio de abordar os pacientes, de obter os dados clínicos e de utilizá-los em sua elaboração teórica. Elaboração esta baseada em relatos dos casos encontrados na Infirmerie Spéciale des Alienés, da chefatura de polícia (onde trabalhou desde 1905, como residente, até 1934, ano de sua morte, já como médico chefe desde 1920), uma instituição que recebia as urgências psiquiátricas, médico-legais de Paris, e cuja função era a de indicar e internar os loucos perigosos. A partir da necessidade de distinguir um apaixonado normal de um delirante mórbido, agravada pela inexistência de uma descrição precisa do quadro, Clérambault consagra o termo Erotomania, baseando-se na observação e abordagem dos quadros em que esses apaixonados insatisfeitos coroavam seus delírios com atos criminosos. 
Na descrição da Síndrome Erotomaníaca (CLÉRAMBAULT, 1993), é preciso destacar o elemento fundamental, que Clérambault aponta como gerador da Erotomania, que seria o Postulado Fundamental: a certeza de estar em comunhão amorosa com um personagem eleito, isto é, a convicção do sujeito de que o outro o (a) ama. O Postulado, por definição, é uma proposição assumida e utilizada fora de demonstração (um termo equivalente ao de axioma). É o elemento que une todos os outros e é aquele em torno do qual giram as interpretações delirantes, determinante de todos os raciocínios, atos e comportamentos. Funcionando como um núcleo estrutural do delírio, é a partir dele que toda a construção delirante a respeito da relação amorosa estabelecida pelo sujeito se dará.

O segundo elemento especial a ser observado na descrição da Síndrome seriam as características do Objeto do amor: em geral, uma pessoa de status mais elevado (social ou intelectual), é ele o responsável (no delírio) pelos avanços amorosos em direção ao sujeito, isto é, foi ele quem começou e que ama mais, ou que ama sozinho. É ele (ou ela) quem se apaixona pelo sujeito, humilde e amado, a par da convicção de que o universo "conspira” a favor desse romance.

Ao lado do Postulado Fundamental, seu elemento central, há ainda outros sinais que Clérambault aponta como característicos da Síndrome Erotomaníaca. Como é possível perceber em outros delirantes, o erotômano tem a ideia de que todas as atenções estão dirigidas a ele, como se houvesse uma disposição universal que favoreceria seu "parceiro" em suas investidas. O delirante crê, ainda, que há uma colaboração geral assegurada em favor do seu pretendente. Este não pode ser feliz sem o pretendido, nem ter nenhum valor sem ele. Em torno disso, há a atitude paradoxal desse pretendente, pois este pode mesmo odiar o erotômano, mas de forma alguma sê-lo indiferente; isto somado à convicção de que, mesmo que pareça odiar, na verdade ele ama. Nessa construção delirante, o Objeto/ pretendente é livre, seu casamento ou qualquer outro relacionamento amoroso não é válido. Há uma interpretação incessante dos fatos atuais e passados pelo sujeito, na qual se destacam os elementos imaginativos sobrepondo-se à razão. É possível observar também reações típicas, como perseguições e viagens: a vigilância, proteção contínua sobre o objeto, tentativas de aproximação, conversas indiretas com este. Pode haver ainda uma evolução regulada, em que o otimismo inicial dá lugar à perseguição e, em seguida, a indícios de querelância.

Apesar da descrição de diversas características que Clérambault considera típicas da Síndrome, este autor aponta a falta de uma univocidade no que diz respeito à erotomania. Por esse motivo, decide dividir a Síndrome em dois tipos distintos. A Erotomania Pura seria um subtipo caracterizado por uma grande intensidade passional e por ser inteiramente calcada no Postulado Fundamental. São quadros em que se verifica com clareza um ponto de partida e nos quais a evolução é mais bem definida. A Erotomania Mista ou Associada seria uma forma mais 
elaborada e complexa, e os casos descritos podem comportar diferentes ocorrências. Corresponderia a casos em que a Erotomania se apresenta prodrômica ou secundária, inclusive relacionando-se a outros fenômenos.

A Erotomania é compreendida (por Clérambault) juntamente com os Delírios de Reivindicação e de Ciúme dentro do grupo dos Estados Passionais Mórbidos. Este agrupamento é consequência de uma dissociação do bloco das paranoias, no qual encontrávamos, de um lado, as psicoses passionais; de outro, o caráter paranoico e os delírios de interpretação e de imaginação. Nas síndromes passionais, há uma ideia diretriz, um núcleo delirante a partir do qual se desenvolvem as elaborações delirantes ulteriores. O passional constrói seu delírio a partir de um estado emocional, ou seja, há um nó ideoafetivo desencadeador, mas que não compromete toda a personalidade. Os delírios interpretativos, ao contrário, dizem respeito ao caráter paranoico, que compromete a personalidade do sujeito de forma global. Não há ideia diretriz, nem nada equivalente ao Postulado, seu início não pode ser tampouco determinado. As convicções são secundárias às inúmeras interpretações.

\section{O CONCEITO DE EROTOMANIA EM FREUD}

Após a descrição da Síndrome Erotomaníaca estabelecida pela abordagem psiquiátrica de Clérambault, é importante estabelecer como o conceito foi abordado pela psicanálise, de início por Freud. É possível perceber que este não se ateve a uma descrição fenomenológica, mas a uma abordagem que Colette Soler define como "uma gramática da libido" (SOLER, 1991).

É particularmente em sua análise do caso do Presidente Schreber (FREUD, 1911/1996) que Freud aponta os sintomas da paranoia como partindo de um mecanismo de defesa contra fantasias de desejo homossexual. Essas estariam no cerne do conflito, nos casos de paranoia dos indivíduos do sexo masculino: a fantasia sexual de "amar um homem". Ele observa que as principais formas de paranoia são representadas por derivações da proposição única "eu (um homem) o amo (um homem)" e seriam convertidas em três formas principais: os delírios de perseguição, a erotomania e os delírios de ciúme. No primeiro caso, ele acredita que a afirmação "eu o amo" seria contraditada e sofreria a transformação para "eu o odeio". Como o mecanismo de formação dos sintomas na paranoia não permite que essa afirmação emirja ao consciente dessa forma, já que as percepções internas devem ser transformadas em externas, a contradição da primeira frase seria transformá-la em "Eu não o amo — eu o odeio — ele me odeia, porque ele me persegue”. A eleição de um perseguidor seria fruto desta construção delirante. E obviamente trata-se de alguém que foi outrora amado. 
No caso da erotomania, a asserção "eu o amo” sofreria uma denegação e se transformaria em “eu a amo”. Através do mecanismo de projeção (em que aquilo que foi abolido internamente retorna desde fora), esta segunda sentença seria então transformada em "Eu a amo, porque ela me ama”, contradizendo assim o próprio objeto. Chama-nos a atenção o fato de que esses sentimentos começam sempre não por qualquer percepção interna de amar, mas por uma percepção externa de ser amado. É importante assinalar que não se trata de um mecanismo de projeção tal como ela se daria na neurose. Essa "projeção" não consiste em imputar ao outro características que são próprias ao sujeito, mas em fazê-las advir de fora, de um outro no qual o sujeito não se reconhece. A projeção na psicose diz respeito a algo que retorna de fora, que está preso na forclusão, “o que foi posto fora da simbolização geral que estrutura o sujeito" (LACAN, 1955-56/1985). A terceira forma de contradição da proposição original seria o delírio de ciúme. Nesse caso, "eu o amo" se transforma em "Não sou eu quem ama o homem - ela o ama”, e, assim, o sujeito suspeita da mulher em relação a todos os homens que ele mesmo possa amar. Nas mulheres, o mecanismo funciona de forma análoga: "Não sou eu quem ama as mulheres - ele as ama”, de forma que ela suspeita do homem em relação a todas as mulheres que ela mesma possa amar.

O que realmente importa no trabalho de Freud, no que se refere à Erotomania, não se restringe, entretanto, a essa acepção gramatical tal como ela se mostra na paranoia. Importa sim, sua forma de perceber o amor, muito antes de Lacan, como algo gerador de impasse: esse embaraço, essa reticência que se apresenta quando entra em jogo a sexualidade. Como nos mostra Alain Badiou (1999), Freud seria o fundador de uma metamorfose no que diz respeito à forma de encarar a sexualidade e, por consequência, sua ligação íntima com o amor. O que nos interessa em Freud, além de sua descrição da Erotomania a partir do caso Schreber, é essencialmente como esse autor nos aponta a contingência que é própria aos destinos das pulsões, como isso tem implicações na sexualidade humana e no que diz respeito à forma como o homem vai em busca de seus objetos de amor, seus pares sexuais.

\section{LACAN E O AMOR COMO SIGNO}

Lacan também não se utiliza da Erotomania como entidade nosográfica autônoma, como fazia Clérambault. A primeira referência de Lacan à Erotomania acontece na publicação de seus primeiros escritos sobre a paranoia, em 1932, em sua tese de doutorado “Da psicose paranoica em suas relações com a personalidade”, na qual analisa o conhecido Caso Aimée. Apesar de fazer menção ao fenômeno erotomaníaco algumas vezes em sua obra, Lacan dedica a maior parte dessas referências a pontuar elaborações já produzidas por Freud e Clérambault. Não há 
nada de realmente novo a respeito da Erotomania como conceito psiquiátrico. O que vai nos interessar na obra de Lacan é a forma como ele elabora uma teoria sobre o amor, que constata uma falta de programação na escolha do objeto amoroso. Utilizaremos esta elaboração para desenvolver a maneira pela qual isso se configura como um impasse na psicose.

Lacan, no Seminário 20 (1972-73/1982), aponta que “o amor faz signo”. Essa é a forma como ele se faz entender. O significante foi uma dimensão introduzida pela linguística, muito utilizada por Lacan no primeiro período de seu ensino para falar da estruturação do Inconsciente. Para manter sua função de significação, o significante deve estar ligado a outro significante, referido em um discurso a certa utilização da linguagem. Ele nunca se apresenta isolado, isto é, não há significante fora da cadeia.

Se o significante é o elemento linguístico que depende da cadeia na qual se encontra inserido, ou seja, se entendemos que ele só pode significar se estiver em uma rede, em relação com outros significantes, o signo, ao contrário, é o que se encontra destacado da cadeia, desarticulado. Como significante desencadeado, suscita a necessidade de produzir uma nova cadeia que lhe dê sentido. Para que a significação possa emergir, é preciso que ele tenha ao seu redor um arranjo de significantes. Por isso, o signo demanda interpretação, pede para ser reinserido na cadeia significante, ser reencadeado, para que, assim, algum sentido possa ser produzido.

O signo, como elemento destacado da cadeia significante, pressupõe a ausência de uma articulação prévia, mas que engaja o sujeito em sua reconstrução. Lacan nos permite entender dessa forma quando comenta, em seu Seminário 8, sobre a Transferência (LACAN, 1960-61/1992), a peça da trilogia de Paul Claudel. A heroína Sygne de Coûfontaine, frente à impossibilidade de articular um "não" como resposta à chantagem do vilão Turelure (que a faria renunciar ao pacto de fidelidade com sua família), antes de sua morte é agitada por um tique facial que assinalava uma negativa (TEIXEIRA, 2006). Signo que acenava para a negação sem jamais ser transformado em palavra.

A paixão amorosa se revela por signos sutis. É o que se pode constatar no encontro do apaixonado com seu objeto de amor, quando os sinais, o silêncio, o olhar, o toque, são todos elementos que urgem por uma interpretação e para os quais o apaixonado constrói todo tipo de sistema de significação. Entretanto, Lacan aponta que o signo do amor difere dos outros signos, pois demanda mais que uma interpretação. Ele tem uma demanda contínua por algo mais, um "maisalém". A demanda de amor revela a sua verdade no incondicional da demanda: o que se busca no objeto de desejo é o desejante. Na verdade, o sujeito busca no objeto de amor algo do próprio sujeito, algo que está perdido de saída, um objeto que jamais será encontrado. O amor é sempre pedido de amor, pedido nunca 
respondido. A demanda de amor fracassa na medida em que o parceiro nunca vai conseguir responder ao outro do ponto em que ele é convocado.

Podemos pensar que o amor busca estabelecer essa unidade impossível, isto é, não se haver com o fato de que não existe programação para a escolha do objeto, a eleição do parceiro amoroso. É nesse sentido que ełe nos permite entender o célebre aforismo de Lacan sobre a não existência da relação sexual. Ainda, a palavra utilizada em francês é rapport, e não relation, e designa muito mais uma relação de proporção, de medida, de rendimento, do que propriamente de ligação ou de conhecimento recíproco (uma relação sexual, não apenas no sentido do coito ou das conexões amorosas). O que não existe então é o rapport sexual (TEIXEIRA, 2006), o que seria, na verdade, a ausência de uma justa medida na relação entre os sexos. Em outras palavras, a falta de uma inscrição simbólica com a qual possamos aferir o par sexual.

O encontro com o parceiro amoroso só se dá pela contingência, pois não há para ele uma programação, apesar de ser assim, sustentado pelo sintoma. O amor seria um signo ininterpretável, pois corresponde à tentativa de ignorar o fato de que não há unidade possível que aplaque a separação entre os sexos. Não há fórmula simbólica, no registro do significante, que redima essa separação. Isso significa dizer que não há um saber no real que dê conta do que é a sexualidade para o ser humano. Assim, sem uma resposta acabada, o homem tem que inventar algo para dar conta da sexualidade, e o faz circunscrevendo esse furo por meio da linguagem. Sem algo que mitigue a não existência de uma programação que determine o encontro sexual, sem uma solução significante plena, a escolha amorosa coloca para o sujeito um enigma. Por isso, o amor quase sempre adquire o aspecto de uma eleição caprichosa.

Já que não há inscrição no real de um saber que diga respeito à sexualidade, o sujeito elabora um sintoma justamente para dar conta desse furo, inerente à inscrição da sexualidade no simbólico. É o sintoma que seduz o parceiro. São elementos, sinais, afetos que provocam no sujeito, através do que ele encontra no parceiro, algo do seu próprio gozo. Dizer que a relação amorosa é mediada pelo sintoma é dizer que o parceiro do sujeito é fundamentalmente algo dele próprio, a forma como ele se acomoda ao não rapport sexual. Mas é importante lembrar que o parceiro do ser humano não se restringe ao par amoroso, ele é multifacetado - o sujeito está sempre engajado em uma partida, sempre ligado a esse parceiro, que é para ele muitas vezes enigmático, causador de problemas. E disso o sujeito goza repetidamente, em sua forma sintomática, para recobrir suas muitas faces.

Mas afinal do que se trata no amor? O amor visa o impossível do rapport sexual, na tentativa de fazer um só, a tensão para fazer Um (LACAN, 1972-73/1982). Como o objeto de desejo nos remete a uma impossibilidade (pois este diz respeito ao 
inalcançável, àquilo que está sempre além ou aquém da demanda), o amor demonstra sua insatisfação. Ele tenta ignorar essa possibilidade de estabelecer uma relação unívoca entre os dois sexos. O discurso analítico se sustenta justamente nesse pilar, já que o amor é o móvel de todo o processo da análise. É algo que a experiência analítica testemunha a todo o momento. O que o ser humano faz é dar uma resposta sintomática ao problema da não existência de medida na relação entre os sexos. Dessa forma, o rapport sexual só existe sintomaticamente.

A escolha do parceiro sexual coloca um dilema, que o sujeito tenta solucionar. Uma solução só ocorre pela mediação do sintoma. Isso é o que facilmente constatamos na clínica da neurose: o desencontro, a tentativa do sujeito de traduzir o que diz seu parceiro. A resposta do sujeito neurótico ao impasse instituído por essa imprevisibilidade do amor consiste na tentativa de negar essa virtualidade enigmática da escolha (TEIXEIRA, 2006), tentar apagar a dimensão da contingência. Ao contrário do sujeito psicótico — que confere à contingência o lugar que lhe cabe num sistema lógico, o lugar do Postulado (tal como nos aponta Clérambault), cuja função axiomática, não dedutível, determina todo o desenvolvimento delirante - , o neurótico se esforça em dar um contorno significante a esse impasse. Por isso, é comum nos depararmos com tentativas de explicação que beiram o cômico, como as ideias de predestinação ("foi o destino que nos uniu”), da existência de "almas gêmeas", além, inclusive, das constrangedoras teorias biologizantes, que tentam estabelecer um controle dos sentimentos amorosos por meio da ação hormonal ou da constituição genética. Frente aos desencontros, o neurótico tenta estabelecer soluções simbólicas e construir um sistema explicativo: “o que foi que eu disse?”, “o que será que eu fiz?”, "o que deixei de dizer?”, etc.

É claro que, quando nos referimos a essa aparelhagem simbólica construída para contornar o embaraço amoroso, falamos de uma posição que atribuímos à neurose obsessiva. O sujeito obsessivo se esforça para apagar a contingência inerente à escolha amorosa, tecendo em torno desse furo que se apresenta um sistema de explicação. Ele se exaure tentando deduzir a dimensão do amor que não obedece às leis significantes.

Se o que se trata no amor é de que o sujeito perceba no parceiro um tipo de saber que responda ao enigma, à inexistência de uma programação para o encontro, o amor supõe a percepção, no parceiro, do sintoma que ele elaborou para dar conta desse enigma.

\section{A RESPOSTA NEURÓTICA E O AMOR DE TRANSFERÊNCIA}

Como a mais radical e misteriosa das relações entre os sujeitos, o amor está no cerne da experiência analítica. Ele está presente de saída e ali exerce sua função. 
Mesmo que confuso e obscuro, é do amor que depende o seu começo e todo o seu desenvolvimento. Desde os primórdios da psicanálise já é possível perceber que a experiência analítica trata de um enredo amoroso.

O caso Anna O. deve ser levado em conta por sua importância inaugural no que diz respeito ao entendimento da histeria como eixo fundador de todo o desenvolvimento da psicanálise. Freud faz uma descrição detalhada do que ocorreu no final do tratamento de Anna O., e os motivos que levaram a sua interrupção, no seu relato a Ernest Jones, conforme publicado no livro sobre sua vida e obra. Há aí uma discussão acirrada entre os historiadores que se ocuparam deste momento da história da psicanálise, mas vamos nos ater à versão descrita por Freud e publicada por Jones (1961/1975). Segundo esta versão, quando o tratamento havia atingido algum sucesso, a paciente começou a manifestar para Breuer uma forte transferência de natureza inconfundivelmente sexual. Este teria, então, se assustado com o caráter sexual da transferência amorosa que a paciente passou a lhe dirigir; notadamente, uma gravidez nervosa (pseudocyesis) teria surgido neste momento. Ainda de acordo com o relato, Breuer teria imediatamente interrompido o tratamento e partido para uma viagem a Veneza com a esposa, onde teria sido concebida sua filha Dora.

Segundo essa versão da história, o tratamento de Anna O. e as demandas amorosas que passaram a ser dirigidas ao seu médico teriam começado a ameaçar seu bem-sucedido casamento. Para Freud, foi este o motivo que fez com que Breuer postergasse a publicação deste caso clínico durante anos, e que, mais tarde, rechaçasse qualquer teoria sobre os impulsos sexuais na constituição psíquica da neurose e mesmo as teses sobre o amor de transferência.

Divergências eventualmente começaram a existir entre Freud e Breuer, que se iniciaram no âmbito teórico e acabaram por se estender para o plano particular, minando os laços afetivos existentes entre os dois. Entretanto, a oposição que de fato culminou no rompimento destas relações foi causada justamente, segundo interpretação do próprio Freud, pelos obstáculos enfrentados por Breuer na análise de Anna O.. Breuer insistia em dizer que, no tratamento de sua paciente, o elemento da sexualidade era inexistente e surpreendentemente não desenvolvido, não apresentando material relevante para o quadro clínico.

No entanto, o papel desempenhado pela sexualidade não apenas era levado em consideração por Freud, como posto em primeiro plano. Para Freud, após o alívio dos sintomas de sua paciente, Breuer teria sido surpreendido pelo desenvolvimento de sentimentos com alta carga sexual proferidos por Anna em sua direção, ou seja, teria, de alguma forma, percebido a motivação sexual que permeava a transferência. Ainda assim, optou por deixar escapar esse fenômeno inesperado, interrompendo suas investigações e considerando-o apenas um "fato inconveniente” (FREUD, 1914/1996, p.22), rechaçando-o. Ao apresentar suas 
teorias sobre a etiologia sexual das neuroses, Freud foi contrariado de maneira veemente por Breuer, que logo manifestava reações de desagrado e repúdio. É sabido que, para Freud, uma das descobertas fundamentais do trabalho analítico sempre foi o caráter francamente sexual das forças impulsionadoras das neuroses e a maneira pela qual estas se atualizavam no tratamento sob a forma de sentimentos hostis ou de afeição, mesmo que isso não fosse desejado nem induzido pelo médico nem pelo paciente.

Tentando solucionar (clinicamente) essa questão, Freud se debruça sobre a transferência, e percebe que a transferência erótica era, na verdade, um pedido para que o analista correspondesse a uma demanda de amor. Se esse amor for satisfeito, o trabalho analítico fracassa. $O$ analista não deve perder de vista o fato de que o objeto de amor de que se trata no trabalho analítico não é a sua pessoa. A transferência, que a princípio se configura como o maior entrave ao trabalho analítico, sendo habilmente manejada, transforma-se no seu mais poderoso aliado.

Em outras palavras, é da construção de certa história de amor de que se trata. Pois a transferência é justamente o lugar para o qual o sujeito neurótico direciona sua demanda de amor. A existência de um Outro a quem o sujeito enderece uma demanda e suponha um saber, faz com que o neurótico mantenha sua crença na existência de uma solução significante que dê conta dos embaraços causados pela contingência inerente ao encontro amoroso. A situação analítica é, sim, um "leito de amor" (como nos afirma Lacan no Seminário XI), no qual exerce sua função, mas cuja posição é paradoxal e cria o contexto falso, pois o que está em causa, na relação analítica, é que é demandado a outro que ensine algo da falta do próprio sujeito.

O neurótico, então, acreditando que o Outro detenha essa resposta, tenta dar um contorno significante a esse impasse. Faz isso porque, ao contrário do psicótico, o neurótico possui esse recurso simbólico, esse refreamento, um ponto de estofo que lhe permite selecionar os elementos relevantes, e não ser inundado pela infinita possibilidade de significação que a realidade oferece e da qual ele se serve.

\section{O SUJEITO PSICÓTICO E A EROTOMANIA}

O sujeito psicótico dá à questão do amor uma solução outra, diferente da neurose, em que o amor é demanda de ser amado pelo Outro. O psicótico não ignora a existência da dimensão contingente e dá a isso seu lugar no sistema simbólico: ele tem uma verdade revelada através do Postulado. Contrariamente ao neurótico, ele não se esforça em construir um sistema explicativo que possa dar conta do que não existe. 
O psicótico tem seu mundo povoado de signos prontos para serem encadeados e, para ele, os sinais que povoam o mundo estão voltados para si. Torna-se, assim, uma máquina de significar. Eles se encontram, de certa forma, imersos em uma nuvem de signos que devem tratar (CONRAD, apud TEIXEIRA, 2006). Na experiência dita normal, há algo que se encadeia previamente e que permite que o sujeito selecione aspectos relevantes da normalidade daqueles que não o são. Mostra-se pertinente estabelecer essa distinção, na medida em que essa forma diferente de relacionamento com a linguagem se faz presente na maneira que ambos têm de lidar com a questão que se apresenta ao ser humano pelo amor.

Com isso, é interessante pensar nas consequências clínicas dessas diferentes posições que podem ser assumidas pelo sujeito frente à questão do amor, pois, se nos pautarmos pela clínica, podemos afirmar que é comum que o encontro amoroso desencadeie a psicose.

Como sabemos, na psicose, há algo que, em certo momento, não se realiza no domínio do significante, é forcluído (verworfen). Assim, dizemos que o Nomedo-Pai como função simbólica é forcluído, pois não é instaurado como portador da lei. A partir da falta deste significante, juntam-se a ele todas as significações que seriam possíveis. Em certo momento, isso que é falho intervém e interroga o sujeito. O desencadeamento advém neste ponto, quando não há ordenamento significante que possa responder a essa questão que lhe foi posta.

É pelo fato de o psicótico não possuir um arcabouço simbólico que dê conta desse enigma que ele constrói um sistema delirante: não pode fazer o Nome-doPai responder em seu lugar, pois ali nunca esteve. Dessa forma, se o encontro amoroso se apresenta para o sujeito como uma atualização desse furo - o que Lacan chamará de "o surgimento de Um-Pai" no texto De uma questão preliminar a todo tratamento possível da psicose (1955-56/1985) — , isto é, a reconstituição de uma estrutura edipiana para a qual ele não tem resposta, pode haver o desencadeamento da psicose. Esse Um-Pai pode assumir qualquer configuração, seja como no caso do Presidente Schreber e a sua nomeação ao Tribunal de Alçada de Dresden, seja no caso Aimée, com sua primeira gravidez, quando dá à luz um filho natimorto.

Para que a psicose seja desencadeada, é preciso que esse significante que foi forcluído seja invocado em algum ponto da vida do sujeito. Esse significante seria indispensável como ordenador de uma cadeia, e funcionaria como ponto de basta para as significações, instaurando a lei da linguagem. O desencadeamento do delírio começa a partir do momento que a iniciativa vem do Outro, algo retorna para o sujeito no lugar do significante Nome-do-Pai forcluído. Quando o sujeito se vê confrontado com o buraco causado pela falta dessa amarração simbólica, quando ele precisa lançar mão deste recurso simbólico, ele não pode fazê-lo, pois para isso não há apoio. A falta do significante Nome-do-Pai nesse lugar abre 
um furo na cadeia que dá início a uma enxurrada de significações que só podem ser ordenadas imaginariamente.

O Nome-do-Pai é convocado pelo sujeito no único lugar onde nunca esteve. Não se trata de um pai real, mas sim de Um-Pai: o que falta é a função, que poderia ser encarnada por qualquer um que instaurasse essa lei, não forçosamente o pai real. É necessário ainda que esse Um-Pai seja chamado num lugar em que o sujeito não pôde chamá-lo antes (LACAN, 1955-56/1985).

Por isso, por não ter esse significante que ordena uma cadeia e que permitiria construir um sistema explicativo simbólico, o sujeito psicótico não pode fazer outra coisa senão dar a essa dimensão contingente o seu lugar devido, o do Postulado. O Postulado como elemento axiomático estará no início de qualquer dedução e irá determinar todas as interpretações ulteriores. Na Erotomania, como já vimos na descrição de Clérambault, a convicção de que “o(a) outro(a) ama” é que vai determinar a construção delirante e todos os comportamentos do sujeito daí em diante.

Ao mesmo tempo em que pensamos em uma vertente desencadeadora, em que o encontro amoroso precipitaria o encontro com Um-Pai e assim, a resposta do sujeito seria dada através do Postulado da Erotomania, é possível ponderar que o amor se prestaria também a uma solução estabilizadora. Deslocado para uma dimensão assintótica, isto é, recuada no infinito, como possibilidade distante, o amor teria uma função de certa forma análoga àquela que Kant atribui ao Ideal regulador. Esse ideal é regulador, pois, segundo Kant, é o que dá a estrutura ao ato contínuo do conhecimento, imprimindo nele um movimento adiante — o absoluto incondicionado que nunca será dado pela experiência sensível, impossível e inalcançável. Para Kant, a busca pelo absoluto é o móvel do conhecimento por ser uma necessidade da Razão, e por isso ele é regulador. Um ideal ao qual o conhecimento aspira não pode jamais ser alcançado, pois todo problema sempre gerará outro problema, toda causa tem efeitos que se ligam a outras causas, e assim incessantemente.

Este é o ponto que merece destaque, pois na possibilidade de o amor ocupar um lugar análogo na vida psíquica, em se tratando da psicose, o amor viria a regular a forma de existência do sujeito, na medida em que se coloca para além da experiência, em um recuo ao infinito, num lugar imprescindível, porém inalcançável.

Em certo sentido, podemos tomar o caso de Schreber como paradigmático. Mesmo que precariamente, temos que admitir que Schreber dá sua missão uma solução assintótica, ou seja, que se realizará num momento recuado ao infinito (de transformar-se em mulher, para redimir o mundo e os homens frente a Deus e procriar para a criação de uma nova humanidade. Schreber se reconcilia com a ideia de sua transformação em mulher, algo que ele coloca em um lugar 
de acontecimento delegado a um futuro distante, se resigna a seu destino e isso provoca uma estabilização).

\section{PERTINÊNCIAS CLÍNICAS DO ESTUDO DA EROTOMANIA}

O amor toca a loucura em algum ponto. ${ }^{1}$ Lacan se dá conta disso já em 1932, ao trabalhar exaustivamente o caso clínico de Aimée. Nos aspectos técnico e clínico, o amor nos interessa a partir do momento que é o que fomenta a transferência. Por isso, ele nos coloca a questão de como essa transferência se dá na psicose: que tipos de embaraços podem ser criados e de que forma o analista pode manejá-los; como o amor de transferência pode nascer e se desenvolver na psicose e como o analista vai responder a isso.

A tarefa do analista é sempre manejar a transferência em favor do trabalho analítico, ainda que ele se encontre frente aos empecilhos gerados pela presença de tonalidades eróticas a ele dirigidas. Apostar no diagnóstico diferencial é o que vai direcionar o tratamento e a posição do analista, embora em ambos os casos (da neurose e da psicose) a transferência deva ser cuidadosamente manejada.

No que se refere à clínica da psicose, tendo em vista a hipótese da possibilidade de regulação pela via do amor, este ocuparia o lugar de um ideal a ser alcançado. A ideia é a de que uma possibilidade de solução seria a inserção, pelo analista, de determinadas medidas, ou mesmo determinadas regras de cortesia, que orientariam e regulariam a situação analítica: em que o Outro se mantém retificado, não ameaçador, relegado ao infinito impossível de ser alcançado. Isso protegeria, então, o trabalho analítico, de certa forma não permitindo que o analista se apresente no lugar do Outro que dele quer gozar — sendo assim, não se transformaria de objeto de amor em Outro perseguidor.

Continuamos concordando com Lacan, por achar que não devemos recuar diante da psicose, apesar da dificuldade de manejo no caso da Erotomania: é imprescindível dar ao sujeito um lugar para falar. Se partirmos do fato de que o delírio é uma construção, uma tentativa de reorganização do funcionamento mental, garantir um lugar de fala ao sujeito psicótico permite que ele possa circunscrever com a palavra aquilo que o invade, que o submete. Reconhecer seu dizer, dar lugar à palavra, é permitir que alguma amarração seja possível, algo que faça um ponto de basta no deslocamento infinito de significação. Assim, esse lugar ocupado pela palavra permite ao sujeito uma solução outra para além da passagem ao ato.

Recebido 14/11/2008. Aprovado 26/10/2009.

\footnotetext{
${ }^{1}$ Extraído do texto de MILLER, J.A. L'amour dans les psychoses (2004).
} 


\section{REFERÊNCIĀS}

BADIOU, A. (2005) Le siècle. Paris: Seuil.

BERCHERIE, P. (1989) Os fundamentos da clínica: história e estrutura do saber psiquiátrico. Rio de Janeiro: Jorge Zahar Editor.

CLÉRAMBAULT, G. G. (1993) L'érotomanie. Paris: Dépôt Legal.

FREUD, S. (1996) Edição standard brasileira das obras psicológicas completas de Sigmund Freud. Rio de Janeiro: Imago.

(1911) "Notas psicanalíticas sobre um relato autobiográfico de um caso de paranoia". v.XII, p.15-89.

(1914) “A história do movimento psicanalítico”, v. XIV, p.15-73.

LACAN, J. (1987) Da psicose paranoica em suas relações com a personalidade. Rio de Janeiro: Forense Universitária.

(1955-1956/1985) O Seminário: livro 3, As psicoses. Trad. Aluísio Pereira de Menezes. Rio de Janeiro: Jorge Zahar Editor.

(1960-1961/1992) O Seminário: livro 8, A transferência. Versão brasileira de Dulce Duque Estrada; revisão de Romildo do Rêgo Barros. Rio de Janeiro: Jorge Zahar Editor. (1972-1973/1982) O Seminário: livro 2, Mais, ainda. Trad. M.D. Magno. Rio de Janeiro: Jorge Zahar Editor.

(1998) “De uma questão preliminar a todo tratamento possível da psicose”, in Escritos. Rio de Janeiro: Jorge Zahar Editor.

MILLER, J. A. (2004) L’amour dans les psychoses. Paris: Seuil.

SOLER, C. (1991) "Fenômenos e estrutura da erotomania". Trad. Elena Lopes Cólb, in Artigos clínicos. Salvador: Fator.

TEIXeIRA, A. M. R. (2006) Signos de amor na psicose. Papéis de Psicanálise, Belo Horizonte, v.2, p.37-40.

(2006) Entre signo e significante: a esquizofrenia incipiente segundo Conrad, Revista do Departamento de Psicologia da UFF, Niterói, v.18, n.1, p.107-116.

Juliana Bressanelli

julibressa@yahoo.com.br

Antônio M. Ribeiro Teixeira

amrteixeira@uol.com.br 